\title{
Development and Evolution of an Interactive HRM Course: A Case Study
}

Lucy A. McClurg, (E-mail: MGTLNM@langate.gsu.edu), Georgia State University

\begin{abstract}
A course in Human Resource consulting ("Human Resources Field Research") was designed and implemented at a university in cooperation with the Society for Human Resource Management (SHRM). Students work with local business executives, SHRM representatives, and the class instructor to complete projects for the client business firms. Trial and error of practices in the class led to evolution of the course to its present state.
\end{abstract}

\section{Background}

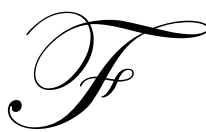

or six years Georgia State University’s Department of Management has been offering a hands-on course called Field Research in Human Resource Management. The course is unique as it involves local businesses, the university, students, and the local and national Society for Human Resources Management (SHRM) chapters. The purpose of the course initially was to more deeply immerse undergraduate students in HR practice and expose them to "real-world" HR problems.

Internships, while valuable and popular with employers and students, were often found to be lacking in challenge, as many interns found themselves performing menial tasks or short assignments that failed to allow them to use a higher level of expertise in a subject. Similarly, class projects in HR content courses involving local businesses were useful, but did not allow for the extensive exposure to HR problem solving. A course giving students the time and resources to study an HR situation in detail and solve HR problems seemed to have great potential for providing value to the undergraduate degree.

A graduate HR Field Research course was already a part of the MBA and MS curriculum for HR majors and was a popular course as an MBA elective, but there was no undergraduate equivalent of the course.

In 1998, the Society for Human Resources (SHRM) Foundation challenged six universities to develop innovative methods to allow undergraduate students more interactive opportunities in the HR field. A "hands-on" approach was sought where students could not only put some of their classroom knowledge and skills into practice but would also encourage them to develop close ties with practitioners. Georgia State University's Beebe Institute of Personnel and Employment Relations accepted the challenge and development of a new course was started immediately.

Participants from the local SHRM chapter (with several thousand members), representatives of the SHRM Foundation, and professors and administrators from the university first met to set criteria for what they hoped the course would accomplish. A "win-win-win” situation was sought. SHRM wanted to be able to identify up-and-coming HR students and to attract top students into the study of HR. The university wanted to give students a meaningful experience in HR practice and an opportunity to apply content from previous HR coursework in a real-world setting. Participating businesses (who would serve as clients) desired resourcefulness and creativity of students in helping them solve their HR problems. 
The potential clients saw the course as a way to accomplish some HR projects they would not normally have time or personnel to undertake.

After much discussion, it was decided that a course devoted entirely to students completing HR consulting projects would best fit the results desired by all parties. Unlike the graduate "HR Field Research" course, the undergrad course would involve HR professionals in the classroom serving as "executives-in-residence" and encouraging networking among students and HR professionals. A proposed syllabus was completed and approved by the university and all parties. In several months, the course was ready for roll-out.

\section{The Participants}

"HR Practicum" was initially co-taught by a regular HR instructor and a member of the local SHRM chapter. The instructor was the student chapter SHRM adviser and had close ties with the local SHRM chapter and with the SHRM Foundation. The SHRM chapter representative submitted a resume to the college and the rest of the participants explicating his credentials and HR experience. The instructor's role was to oversee the entire course, coordinate the activities of the participants, and ensure all requirements for course credit were met, including final grading of students.

The SHRM representative's role was to serve as a resource person in the classroom. Since this person had extensive HR consulting experience, he became a sort of "executive in residence" for the class and provided real world knowledge, expertise, and very valuable lessons on forming relationships with clients.

The SHRM representative recruited business participants through local SHRM meetings and communications and through personal contacts. A number of companies responded to ads in the chapter newsletter to "Take advantage of the today's HR students..." and asked to be a part of the team. In an attempt to keep the course manageable the first time it was taught, it was decided to use only one business client, to be selected by the instructor and SHRM representative, and to hold class size at ten students. The client met with the instructor and SHRM representative on several occasions before the start of classes to specify obligations, responsibilities, and expectations of the client firm.

Students were recruited from other HR classes by the instructor. Flyers informing them about a new course and giving a brief description were distributed in management and HR classes and an application was made available. On the application, students were asked to provide their class status, GPA, HR courses completed and grades in those classes, and work experience. In addition, they were asked to respond to the question, "Do you feel you are good at working in an ambiguous, unstructured situation and in a team environment? If so, please describe situations in which you worked under these conditions and how you reacted." Of some 20 applicants, 10 were selected by the instructor for the first offering of the course.

\section{The Course}

Course scheduling was a concern from the start. We wanted to attract as many top-notch students as possible but also have an opportunity for students to visit the client firm during normal business hours. A one day per week, 4:30-7:00 PM time slot was selected, thus giving both our traditional students, our working students and the business participants a chance to attend the class.

On the first day of class, the instructor met with the students to explain academic requirements of the course. It was decided that the students and instructor should first meet to get to know each other and to allay anxiety about grading requirements before students met the rest of the participants. Students were 
provided with a syllabus explaining in detail how the parties would work together and how grades would be assigned. A suggested reading list was included, but it was emphasized that readings and materials for the class would be determined in light of the client's needs.

As designed by the initial team, the work to be done was prescribed by a contract to be negotiated and signed by the parties, based on the client's needs. This was a novel and somewhat troubling issue for some students who were accustomed to having a precise syllabus and schedule on the first day of class. It was explained that this was part of the purpose of the class: to work with clients to help them articulate their problems and the deliverables that would address those problems.

Although various consulting projects were discussed among the instructor, SHRM representative and business firm prior to the first meeting, the classroom participants were still not aware of the nature of the term project on the first day of class. This was somewhat frustrating to the students, as they wanted to know specifically what they would be doing. It was explained to them that the course would require a great deal of their own initiative and teamwork to complete the course. Students who did not feel they could operate in such an environment were encouraged to drop the course at this time. None selected this option.

Students were then told to organize themselves into a team with various roles, based on their strengths and interests. One student was elected to be the liaison with the client, thus preventing unnecessary communication with the client. Another student was to be in charge of technological needs, another to be responsible for technical writing, and so on. It was decided that in future class periods, an elected student would be in charge of running the class and allocating time to various subjects. A project coordinator was elected to oversee the interrelated tasks.

On the second class meeting, all participants met at the business client's headquarters and were introduced to the class. Students were given background and information about the company and the other participants. Roles and responsibilities were explained and the client presented the assigned project. Students asked a number of questions about expectations and initial negotiations of the terms of the project were begun. The two students elected to negotiate the contract used this class period to set up meetings with company representatives to work on the contract.

During the next several class periods, the negotiators continued to refine the contract for deliverables with the client while the rest of the class proceeded with gathering information related to the subject and brainstorming ways to address the client's problem. Old textbooks and essays were hauled out, the Internet was searched, and students began talking with other members of the profession to get ideas. Once all the parties agreed to the deliverables in the contract, preparation of the consulting report was started. The client sought a formal one-hour presentation to his company's management giving information about the topic (the role of HR in mergers and acquisitions), the client's recent experience with this subject, and recommendations for the company. The presentation was to be accompanied by a collection of materials including interview notes with HR managers at other companies who had experienced a merger, with research results on the effects of mergers, and with case studies of the experiences of others, including best practices during drastic change. The SHRM representative and the instructor worked with students throughout the semester to help identify resources and to put together a professional-quality product for the client.

\section{Benefits of the Course}

On the day of the presentation, top mangers of the business client, university administrators and other faculty, SHRM officers and representatives, and several members of the local business community gathered at the firm's headquarters to hear the final report. Students fielded questions from the audience 
and the audience made suggestions to the students about how the product could be improved. Audience members were asked to provide feedback on the quality of the presentation, and these reactions were used as one input into the students' grades.

In a post-presentation evaluation session, all participants agreed the experience had indeed been "win-win-win" for all parties. Participant, student, and audience feedback were all positive and enthusiastic, with a few exceptions.

Students in both this evaluation session and in the regular course evaluation expressed appreciation for the help and input of the other participants. They were amazed at how approachable and accessible the business client and SHRM members were to them and how closely they were willing to work with them. They were also pleasantly surprised at how much the course challenged them both intellectually and in interpersonal ways. Several who had been ambivalent about HR as a career were now sure this was where they wanted to work. Others who planned to work in other fields (such as accounting and finance) expressed the view that they had a deeper appreciation of and understanding of the HR role in business.

The SHRM representative was grateful for the opportunity to put his considerable expertise and experience into use in the classroom. He was also somewhat surprised at how much he learned from the students and by helping them research the subject they were assigned. On behalf of the local SHRM chapter, he expressed appreciation for the opportunity to become acquainted with some very bright students he was able to steer into the profession. Several students were offered positions with local firms because of the contacts they made in working on the project.

The client was perhaps the most enthusiastic participant. The students completed with great care and thoroughness a project that directly benefited the firm and that the firm would not have had time or manpower to conduct on its own. The perspective and information brought by the students had practical and significant value to the firm. He immediately asked to sign up for another class.

The university HR program was able to strengthen its ties to the local business community and practitioner as well as provide students with an experience they could not have gotten within the four walls of a classroom. The course also gave the instructor a chance to get valuable perspective on the "real world" and to find out more about the concerns and practices of professionals in the field.

\section{Evolution of the Course}

As word spread among local HR practitioners of the success of the course and the pay-offs for participating clients, their interest in becoming involved has grown. The HR faculty decided to change the format of the graduate version of the course to the SHRM-affiliated version. Formerly, the graduate "Field Research" course had consisted of projects suggested by local corporations with no SHRM or practitioner involvement in the day-to-day operation of the course. The networking benefits of the undergraduate course convinced the faculty the SHRM model was a superior one to the present graduate version. The name of both courses became "Field Research in HR."

The numbers of both projects and sponsors has continued to grow as practitioners have become more adept and selecting good topics and as word has spread about benefits of the course for businesses. After all, this is an opportunity for HR departments to get some high-quality free labor and the expertise of other practitioners and faculty members. One client has completed eight projects with students and other firms are coming back for more involvement. As practitioners and "executives-in-residence" and faculty have gotten practice in the course, it has been possible to increase class size and complexity of projects. As many as thirty students and six projects have been undertaken at one time. 
Recently the undergraduate and graduate sections of the course have been combined into one section in response to university budget cuts and pressure from the university to increase class size. We limited the enrollment to 15 undergraduates and 15 graduate students. Graduate students registered for the graduate version of the course and undergraduate for the undergraduate version. Graduate students were assigned additional written work and were held to a higher productivity standard than undergraduates. After some discussion about whether or not to segregate groups and projects by student level, we turned the decision over to the class members to decide. After hearing the details and course requirements on the first day and introducing themselves (and providing information about themselves), the students voted overwhelmingly to allow graduate and undergraduate students to work in the same group. At the end of the semester, there was some dissatisfaction about how this had worked, but there were no significant differences in complaints from grad versus undergrad; rather, there was a small amount of dissatisfaction over the issue from both groups. There was general support, however, for continuing to mix the groups in the future.

\section{Some Surprises and Lessons Learned}

The course continues to be well received by participants, especially by the clients who supply projects. It is interesting to note that all of the fifteen or so projects undertaken so far have been used and implemented by the clients and most are still in use. There have been some surprises and potential problems; however, that deserve close attention if the course is to be a success.

One surprise was how difficult it was to attract some of the best HR students into the class. While some students were quite enthusiastic, others were anxious about the work load, the complexities of working in a group, and the uncertainties of the assignment. Others were fearful of making a bad impression on business representatives and preferred an academic course where they only had to answer to the instructor. As one student stated, "I don't mind looking foolish to an instructor, but I hate to make a spectacle of myself in front of real business people!" Weaker students are sometimes attracted to the class because they see the opportunity to become a free rider in a group project or to receive a good grade. Word of mouth and recruiting by alums of the course has helped to attract good students to the class.

The negotiation and completion of the consulting contract required much more time and effort than anticipated. Students were accustomed to a structured course where a syllabus and schedule were handed out the first day and specific assignments were already planned. Students in this course were forced to first examine the client's problem areas, identify symptoms and potential causes, and then to address the problems. All work had to be completed in a 12-week period, so work load was a major consideration. Clients are sometimes vague about their needs and do not know themselves what specific deliverables they desire. A typical time frame for settling on the final contract and getting all parties to sign off is a minimum of six weeks. Of course, work can begin before the contract is finalized, but there is sometimes a temptation for both students and clients to try to change the terms and deliverables of the contract during the semester.

Another surprise was how easy the grading turned out to be. Initially, students seemed to expect they would all get the same grade for the course and that grade would be an A. To assist in identifying students who made the most and least contribution to the project, students were required to keep a productivity log of tasks completed and time spent on various aspects of the project. This document looked much like a "billable hours" log used by CPA's and lawyers. Feedback by the other participants and students' peer evaluations of each other served to confirm what the productivity logs most often reflected: some students did much more than others and earned significantly higher grades. In the words of one student, "I guess my productivity log told the whole story." The logs were also useful in clarifying which student did what task. In a few cases, multiple students took credit for the same accomplishments. 
The instructor was able to bring them together and ask for evidence they had completed the work, and the non-contributors were soon discovered.

Another potential problem was confidentiality. Client firms must often disclose negative information about themselves or give the class information that could be used by competitors as a strategic advantage. All contracts contain a confidentiality agreement and the parties constantly remind each other of the need for discretion. When outsiders are invited to the final presentation, they are also asked to sign a confidentiality agreement, stating they will not divulge or use information given at the presentation. Students and the client firm usually meet before the presentation to identify topics that the client does not want mentioned in the presentation, and information about these topics is included in a written report to the client.

When the course was adapted for the graduate HR program, the participants were stunned to find how assertive these students could be. After being told (confidentially) of some of the client's problems the class should consider addressing, several members of the class who were themselves consultants or had close ties to consultants contacted the client firm on their own to solicit the client's business. We now include a non-compete clause in the contracts, stating that no participants will use the class connections for personal or professional gain.

\section{Some Recommendations for Others}

Through trial and error, we have learned more about how to make a success of a hands-on course co-taught with a professional organization and feel we can make some humble suggestions to others considering this approach. First, make full use of the professional organization. Our local SHRM chapter (as well as organizations like the AICPA, ASTD, or other professional organizations) is full of highlyregarded practitioners eager to share their knowledge and skills in the classroom. Letting these practitioners take the lead on some of the projects can at times be intimidating and threatening to college faculty who feel they have a scholarly responsibility for the course and its content. The benefits of tapping into their experience, however, are well worth our pride. Organizations like SHRM are almost always strongly committed to educational programs and welcome the involvement with local schools.

The professional organization is also a wealth of contacts for the college. We have generated internships, entry level positions, scholarships, and special programs and seminars with local businesses as a result of this course. Additional members with expertise in a particular area are often brought into the class and welcome the occasion to share their expertise with students. SHRM participants also report that working on the class project strengthened their networking connections with others in the HR community and in some cases helped them develop new career opportunities. Some students decided to abandon a career in consulting temporarily as they discovered first-hand the amount of personal marketing required to negotiate and sell a project.

Second, as alluded to earlier, the instructor should get out of the way and let the students run the show. It is tempting for an instructor (and especially one who has done extensive consulting) to jump in and tell students what they should do and how it should be done. It is important for all parties to know and agree that the students are solely responsible for their work, and unless there are moral or legal problems the instructor should allow students to learn from their mistakes. One frustrating day when the class could not seem to get itself organized or make a decision, one student finally came forward and took over the class. She began handing out assignment and then whirled on the instructor and emphatically stated, "And YOU should sit down and shut up and let us take the consequences for this!" This was a lesson well learned.

It is also very important to carefully screen potential client participants prior to their final 
selection to ensure a challenging and appropriate assignment. Some firms are looking for free student labor instead of a genuine consulting project. Beware firms that express a need for help in "getting our data base straightened out" or those who comment that "Your students can probably get a lot of good information out of our competitors by using their student status in informational interviews.”

Use of professional organizations in for-credit classes can be a rewarding experience for all parties if properly utilized. Too often we only approach these associations for money, while their considerable practitioner talents go to waste. The benefits of a respectful, open involvement with their members far outweigh the time and trouble of coordination required to make them valuable collaborators in the education process. 


\section{$\underline{\text { Notes }}$}

